Infection in man has been reported in milkers working in the pit of the new commonplace herringbone milking parlour, as in this case. The milker works at udder level and is thus liable to be contaminated by urine, either by direct facial splashes or from aerosols generated when the urine falls to the parlour floor. A survey carried out by the Central Veterinary Laboratory and Veterinary Investigation Centre in 1980 showed that about $23 \%$ of cattle in the south west of England have serological evidence of infection with $L$ hardjo. High levels of infection have also been found in other parts of the country.

The possibility is thus very real that milkers using this parlour system may acquire infection from carrier cows who excrete the organism. In humans $L$ hardjo infection has in recent years accounted for about one quarter of all cases of leptospirosis diagnosed in Great Britain. The usual feature of infection with this serotype is the severity of the headache, but occasionally more serious complaints such as meningitis, as in the patients in this outbreak, and even death, may occur. In general, however, $L$ hardjo infections usually give rise to a mild influenzalike illness with a severe frontal headache and a prolonged period of recovery.
Treatment of leptospirosis with antibiotics is controversial. Alston and Broom stated that antibiotic treatment does not benefit patients when, as is usual, it is not begun before the third or fourth day of illness. ${ }^{1}$ There have been many reports of treatment with antibiotics, but little satisfactory evidence that they altered the course or outcome of the disease. The general consensus favours parenteral penicillin in large doses for severe illnesses; the treatment should be continued even if it provokes a Herxheimer effect. ${ }^{2}$ Amoxycillin has emerged as the preferred oral treatment because it is well absorbed. It has been used empirically in a number of $L$ hardjo infections because the illness is often prolonged, but with only anecdotal evidence that it is effective in shortening the course of the disease. The usual dose is $500 \mathrm{mg}$ three times daily for five days.

\section{References}

1 Alston JM, Broom JC. Leptospirosis in man and animals. Edinburgh: $\mathrm{E}$ and S Livingstone, 1958:198.

2 Turner LH. Leptospirosis I. Proc Roy Soc Med Hyg 1967;61:842-55.

\title{
Leptospirosis in man, British Isles, 1983
}

\author{
Prepared by the Public Health Laboratory Service Leptospira Reference Unit and the Public Health Laboratory Service Communicable \\ Disease Surveillance Centre
}

During 1983, 120 cases of leptospirosis were confirmed by the Leptospira Reference Unit, almost double the 1982 figure of $61 .^{1}$ Four patients died. Eight infections were thought to have been contracted abroad, all in soldiers. Of the remaining 112 patients, 77 contracted the infection in England, five in Wales, four in Scotland, five in Northern Ireland, one in the Channel Islands, and 20 in the Republic of Ireland.

Cases are classified by serogroup and age of patient in the table;

Age and serogroup

\begin{tabular}{|c|c|c|c|c|c|c|c|c|c|}
\hline \multirow[b]{2}{*}{ Serogroup } & \multicolumn{8}{|c|}{ Age (years) } & \multirow[b]{2}{*}{ Total } \\
\hline & $\leqslant 14$ & $15-24$ & $25-34$ & $35-44$ & $45-54$ & $55-64$ & $\geqslant 65$ & $\begin{array}{l}\text { Not } \\
\text { stated }\end{array}$ & \\
\hline $\begin{array}{l}\text { Icterohaemorrhagiae } \\
\text { Hebdomadis } \\
\text { Canicola } \\
\text { Other } \\
\text { Not determined }\end{array}$ & $\begin{array}{l}2 \\
1 \\
1\end{array}$ & $\begin{array}{l}10^{*} \\
8 \\
3 \\
2 * * \\
3\end{array}$ & $\begin{array}{c}5 \\
16^{*} \\
1 \\
2^{* *} \\
1^{*}\end{array}$ & $\begin{array}{c}5 \\
16 \\
1 \\
1 * \\
2\end{array}$ & $\begin{array}{l}3 \\
6 \\
2\end{array}$ & $\begin{array}{r}10 \\
7\end{array}$ & 2 & $\begin{array}{l}2 \\
2\end{array}$ & $\begin{array}{r}39 \\
55 \\
8 \\
5 \\
13\end{array}$ \\
\hline Total & 4 & 26 & 25 & 25 & 14 & 18 & 3 & 5 & 120 \\
\hline
\end{tabular}

*Case infected abroad.

the total includes six infections in girls and women: a 23 year old with Icterohaemorrhagiae, a 21 year old with Hebdomadis, three patients aged 9, 34, and 47 years with Canicola, and one 48 year old for whom the serogroup was not stated. Of the 55 patients infected with Hebdomadis serogroup leptospiras, all but one belonged to serotype hardjo, which is associated with cattle: 26 of these patients (24 in England) had contact witt. infected herds, and in four of these incidents more than one case (two to four) occurred on a single farm. The fourfold increase in reports of this serotype since 1982 is thought to be largely due to increased awareness of the risk of infection among the farming community, especially those working with dairy cattle. An article on the subject appeared in a farming journal during the early summer of 1983. Three regions-South Western, West Midlands, and Oxford-recorded half of the 54 hardjo infections.
The number of Icterohaemorrhagiae serogroup infections also increased, from 23 in 1982 to 39 in 1983.

Eight patients with leptospirosis (all male) contracted their infection abroad: three in Belize (one Icterohaemorrhagiae, two Bataviae), three in Brunei (one Australis, one Hebdomadis, one not determined), one in Seychelles (Australis), and one in West Germany (Grippotyphosa).

The disease showed the same well defined seasonal pattern as in previous years. Ninety six cases were reported in the six month period from June to November with peaks in July (23) and October (19). The remaining seven cases had onsets before the year under review. In Icterohaemorrhagiae infections there was a definite high plateau of cases in the three month period August to October, during which 22 of the 39 cases occurred, whereas Hebdomadis infections showed two peaks of incidence, with 21 cases in June/July and 19 in October/November.

Of the 39 patients with Icterohaemorrhagiae infection, 21 had both jaundice and renal failure (four also had meningitis), six had jaundice (one with meningitis), three had renal failure (one with meningitis), one had meningitis only, and two had an influenza like illness; in six the symptoms were not stated. In contrast, the following symptoms were reported in 55 patients with Hebdomadis infection: 16 had meningitis only and 28 an influenza like illness; one had renal failure and jaundice, one renal failure alone, three jaundice alone, and one jaundice and meningitis. In the remaining five the symptoms were not stated. The symptoms recorded in the eight patients with Canicola infections were characteristic of the serogroup: six had meningitis alone, one meningitis with renal failure, and one renal failure alone.

Leptospirosis in Britain is mainly seen in men; this preponderance was particularly marked this year. The distribution of cases among age groups was also typical, with only seven of the 115 cases for which the age was stated not of working age (15-64 years); none of the seven belonged to the almost entirely occupationally acquired cattle associated group of hardjo infections. 
Forty of the patients were engaged in farm work with cattle and 35 of these had hardjo infections. There were seven other patients, not farmers, who worked with cattle, and six had hardjo infections. Of the 12 patients who did farm work but had no contact with cattle (or none stated), six had hardjo infections.

Eighteen patients gave a history of immersion in (presumably rat contaminated) water: 13, comprising six canoeists, four swimmers, two anglers, and a windsurfer, had Icterohaemorrhagiae infection. Occupational Icterohaemorrhagiae infections occurred in 10 farm workers, one miner, one sewer worker, and one laboratory worker; there was a history of rat contact, not specifically occupational, in five cases. Contact with dogs, including one shown to be infected, was recorded in five of the eight cases of Canicola infection.

\section{$L$ hardjo infection in cattle}

There was a gradual increase in the number of outbreaks of bovine leptospirosis diagnosed by the veterinary investigation centres in England, Wales, and Scotland, from 78 incidents in 1978 to 144 in 1982 . In 1983 the number of incidents rose sharply to more than 500 . The proportion of cattle sera tested at the
Central Veterinary Laboratory that gave a positive result to the $L$ hardjo microscopic agglutination test in 1983 was similar to that in previous years. This suggests that there has not been a real increase in bovine leptospirosis but rather a recent increase in awareness to which three factors have contributed. Firstly, since the virtual eradication of Brucella abortus from cattle other causes for bovine abortion are being sought, and leptospirosis is currently the most common diagnosis. Secondly, fluorescence antibody tests for $L$ hardjo on bovine fetal tissue are now widely used and have replaced the less sensitive serological microscopic agglutination test, which was sometimes negative by the time a cow aborted. Finally, the marketing of $L$ hardjo vaccines for cattle since mid 1983 has provided a means for control of this infection, thus giving another reason to establish a diagnosis where leptospirosis is suspected. This may well be the most important factor in the recent increase in incidents reported.

\section{Reference}

${ }^{1}$ Leptospira Reference Unit and the Communicable Disease Surveillance Centre (Public Health Laboratory Service). Leptospirosis in man, British Isles, 1982. Br Med f 1983;287:1365-6.
A man with fairly advanced ankylosing spondylitis is dependent on steroids. He has been treated in the past with radiotherapy to the spine. Pain occurs in both knees and at the insertion of the left Achilles tendon when he attempts tc reduce the dose of steroids (15 mg prednisolone daily). Nonsteroidal anti-inflammatory agents fail to control his symptoms. Is there any way of reducing his oral steroids; and would radiotherapy help?

Yes. Radiotherapy might well help-though its long term benefit is questionable. After the Doll report on the increased incidence of leukaemia following irradiation for ankylosing spondylitis, this form of treatment almost ceased. For reasons which remain obscure, however, irradiation does help certain people with seronegative arthritis. The pendulum has begun to swing back to its localised use-particularly for the intractable Achilles or plantar fasciitis mentioned in the question. In 1980 we reported five patients with persistent and disabling pain in the heels who were treated with local irradiation. ${ }^{1}$ Four showed not only sustained clinical improvement, but scintigraphs of the affected regions also improved.-G R V HUGHES, consultant physician and reader in rheumatology, London.

Sewell JR, Black CM, Chapman AH, Stathan J, Hughec GRV, I avender JP. Quantitative scintigraphy in diagnosis and management of plantar fascitis. f Nucl Med 1980;21:633-6.

Is there any evidence that chlorpromazine affects future fertility (a) if given to children and adolescents $(b)$ if given to adults?

Chlorpromazine effects several aspects of reproductive function. It can produce both impotence and ejaculatory impairment, increase serum prolactin concentrations, and, in vitro, inhibit human sperm motility. ${ }^{1}$ The effect of drug induced elevation of prolactin levels on fertility is unknown. Inhibition of sperm motility has been described only in vitro and, though concentrations of chlorpromazine in seminal fluid achieved during treatment are unknown, they probably would not be sufficient to inhibit sperm motility and thus cause infertility in vivo. ${ }^{1}$ I am not aware of any clinical evidence that fertility is impaired in patients taking chlorpromazine. On the contrary, there is some evidence that the introduction of neuroleptic drugs has been associated with an increase in the reproductive rates of schizophrenics, ${ }^{2}$ and though this is almost certainly not a direct effect of these drugs, it perhaps provides some reassurance that these do not commonly cause infertility.- LINDA BEELEY, consultant clinical pharmacologist, Birmingham.

Hong CY, Chaput de Saintonge DM, Turner P. Effects of chlorpromazine and other drugs acting on the central nervous system on human sperm motility

Eur $\mathcal{Y}$ Clin Pharmacol $1982 ; 22: 413-6$.
Erlenmeyer-Kimling L, Nicols S, Rainer JD, Deming WE. Changes in fertility rates of schizophrenic patients in New York State. Am $\mathcal{f}$ Psychiat 1969;126:
What precautions are taken to ensure that hepatitis $B$ immunoglobulin is not taken from individuals who may have acquired immunodeficiency disease?

A WHO Consultative Group in May 1983 confirmed, after assessing all the data assembled, that at present there is no evidence of risk of acquired immunodeficiency disease attached to the use of normal or specific immunoglobulins prepared by universally accepted methods. ${ }^{1}$ British specific hepatitis $B$ immunoglobulin is prepared, by the modified Cohn fractionation method, ${ }^{2}$ from the blood of voluntary donors in the United Kingdom who are found to have high titres of antibody to hepatitis B surface antigen. Large amounts of this immunoglobulin for intramuscular use have been distributed over many years, and there have been no reports of associated infection of any type. Nevertheless, as an extra precaution, the National Blood Transfusion Service requests donors not to give blood if they or their sexual contacts are suffering from acquired immune deficiency disease or if they belong to groups at risk of acquiring it, such as promiscuous homosexual men and parenteral drug abusers.- SHEILA POLAKOFF, consultant epidemiologist, London.

1 World Health Organisation. Weekly Epidemiological Record 1983 August 5. Nitschmann H, Kistler P. Large scale production of human plasma fractions.
Vox Sanguinis 1962;7:414-24.

I find that gin and tonic averts cramp. Is this effect the result of the alcohol or the quinine in the tonic? If the latter how much quinine is contained in a standard gin and tonic and what is a toxic dose of quinine?

I am not aware of any evidence that alcohol is of any value in preventing cramp. Tonic water contains about $80 \mathrm{mg}$ of quinine per litre ${ }^{1}$ so a standard gin and tonic would probably contain around $10 \mathrm{mg}$. The usual dose of quinine for the prevention of cramp is $200-300 \mathrm{mg}$ at night as quinine sulphate (equivalent to $194-291 \mathrm{mg}$ of quinine), but so far as I know the lowest effective dose has never been determined. It seems unlikely that a single gin and tonic would contain sufficient quinine to prevent cramp but possible that several might. The average fatal dose of quinine is about $8 \mathrm{~g}$ (range 3-31 $\mathrm{g}$ ). A single dose of $4 \mathrm{~g}$ usually produces toxicity, as can prolonged use of full therapeutic doses. ${ }^{2}$ Other adverse effects such as rashes and thrombocytopenia occur with very much smaller doses and have been described after ingestion of tonic water. ${ }^{2}$ The consumption of large quantities of tonic water apparently potentiated the effect of warfarin in one case. ${ }^{1}$ - LINDA BEELEY, consultant clinical pharmacologist, Birmingham.

1 Clarke JD. Clinical curio: warfarin and tonic water. $\mathrm{Br} M$ Med $\mathcal{f}$ 1983;286:1258. Martindale's Extra Pharmacopoeia. 28th ed. London: Pharmaceutical Press, 